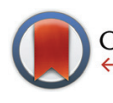

CrossMark \&lick for updates

Cite this: Dalton Trans., 2015, 44 13156

Received 3rd April 2015, Accepted 10th June 2015

DOI: $10.1039 / \mathrm{c} 5 \mathrm{dt} 01284 \mathrm{~h}$

www.rsc.org/dalton

\section{Novel helical assembly of a Pt(II) phenylbipyridine complex directed by metal-metal interaction and aggregation-induced circularly polarized emission $\dagger$}

\author{
Toshiaki Ikeda, ${ }^{a}$ Midori Takayama, ${ }^{a}$ Jatish Kumar, ${ }^{\mathrm{b}}$ Tsuyoshi Kawai ${ }^{\mathrm{b}}$ and \\ Takeharu Haino*a
}

\begin{abstract}
Pt(I) phenylbipyridine complexes possessing bis(phenylisoxazolyl)phenylacetylene ligands self-assembled to form stacked aggregates via $\mathrm{Pt}-\mathrm{Pt}, \pi-\pi$ stacking, and dipole-dipole interactions. The assembled structures were influenced by the solvent properties. Non-helical assemblies found in chloroform displayed metal-metal-to-ligand charge transfer absorption and emission, whereas helical assemblies formed in toluene showed aggregation-induced enhancement of emission and aggregation-induced circularly polarized luminescence. The rates of the association and dissociation of the assemblies were significantly reduced in toluene, and the non-helical structures formed in chloroform were surprisingly memorized.
\end{abstract}

\section{Introduction}

Self-assembly of functional molecules offers a powerful tool for the development of discrete supramolecular organizations that display fascinating characteristics, such as optical, magnetic, mesogenic, and macroscopic properties. ${ }^{1}$ During selfassembly, reversible intermolecular interactions bind the molecular components together to define the direction and dimension of the target molecular organizations. Thus, selfassembly of molecular components in a desired manner can enable the generation of tailored functional organizations with the required properties. A variety of intermolecular interactions have been applied to the self-assembly. Reversible metallophilic interactions of $\mathrm{d}^{8}$ - and $\mathrm{d}^{10}$-metals, including $\mathrm{Au}-$ $\mathrm{Au},{ }^{2} \mathrm{Pd}-\mathrm{Pd},{ }^{3}$ and $\mathrm{Pt}-\mathrm{Pt}^{4}$ interactions, have received significant attention due to the development of polymeric linear metal arrays with unique photochemical properties and mesoscopic behaviors. ${ }^{5}$ Particularly, self-assemblies of square-planar Pt(II) complexes have displayed excellent phosphorescent properties. Although many self-assemblies of cationic Pt(II) complexes through Pt-Pt interactions have been reported, ${ }^{4}$ reports on the

${ }^{a}$ Department of Chemistry, Graduate School of Science, Hiroshima University, Higashi-hiroshima 739-8526, Japan. E-mail: haino@hiroshima-u.ac.jp

${ }^{b}$ Graduate School of Materials Science, Nara Institute of Science and Technology, Nara 630-0192, Japan

$\dagger$ Electronic supplementary information (ESI) available: Results of TD-DFT calculation, spectroscopic data, photographs, AFM images, and copies of ${ }^{1} \mathrm{H}$ and ${ }^{13} \mathrm{C}$ NMR spectra for the reported compounds. See DOI: 10.1039/c5dt01284h self-assembly of uncharged Pt(II) complexes in a common organic solution have been limited. ${ }^{6}$

We have reported that tris(phenylisoxazolyl)benzenes assemble to form helical assemblies, displaying unique photonic properties. ${ }^{7}$ During the course of the studies, the intermolecular dipole-dipole interaction of the isoxazolyl moieties has been crucial for developing the supramolecular helical assemblies. We envisioned developing a dimensionally organized platinum array via self-assembly of the neutral platinum complex with the aid of the intermolecular dipole-dipole interactions. In this study, new Pt(II)phenylbipyridine complexes possessing the bis(phenylisoxazolyl)phenylacetylene ligands $S$ - and $R$-1, showing unusual aggregation-induced enhancement of emission (AIEE) and strong aggregation-induced circularly polarized luminescence (AICPL) are described (Scheme 1).



Scheme 1 Structure of molecules $S$ - and $R-1$ and schematic representation of their self-assemblies in chloroform and in toluene. 


\section{Results and discussion}

Synthesis

The synthesis of Pt(II) phenylbipyridine complexes $S$ - and $R-\mathbf{1}$ is shown in Scheme 2. Bis(phenylisoxazolyl)phenylacetylene ligands $S$ - and $R$-4 were synthesized via 1,3-dipolar cycloaddition of 1,3,5-triethynylbenzene 2 with the $p$-alkoxyphenylnitrile oxides prepared in situ from the corresponding hydroximinoyl chlorides $S$ - and $R-3$ by the treatment of triethylamine. Ligands $S$ - and $R-\mathbf{4}$ were introduced to the platinum center of $\mathbf{5}$ through a ligand exchange reaction catalyzed by copper(I) ion to afford the desired products $S$ - and $R \mathbf{- 1}$.

\section{Self-assembly in chloroform}

The self-assembling behavior of $S$-1 in chloroform-d ${ }_{1}$ was studied using ${ }^{1} \mathrm{H}$ NMR spectroscopy. The ${ }^{1} \mathrm{H}$ NMR signals of $S$-1 were concentration dependent (Fig. 1 and S2 $\dagger$ ). Aromatic protons $\mathrm{H}_{\mathrm{a}}-\mathrm{H}_{\mathrm{p}}$ shifted upfield by increasing the concentration from 1.0 to $26.0 \mathrm{mmol} \mathrm{L}{ }^{-1}$, indicating that $S$-1 formed stacked assemblies in which the aromatic protons are placed in the shielding regions produced by the aromatic rings of a neighboring $S$-1. A plot of the chemical shift changes of the protons versus the concentrations of $S$-1 produced hyperbolic curves. Non-linear curve-fitting analysis by applying the isodesmic model produced the estimated assembly-induced shifts $(\Delta \delta=$ $-0.57,-0.20,-0.04$, and -0.08 ppm for $\mathrm{H}_{\mathrm{a}}, \mathrm{H}_{\mathrm{l}}, \mathrm{H}_{\mathrm{n}}$, and $\mathrm{H}_{\mathrm{p}}$, respectively) and the association constant $\left(K_{\mathrm{E}}=93 \pm 8 \mathrm{~L}\right.$ $\mathrm{mol}^{-1}$ ). The phenylbipyridyl protons displayed larger upfield shifts than those of the other aromatic rings (Table S1 $\dagger$ ). These findings implied that $S \mathbf{- 1}$ stacked as piles along with the platinum center. The association constant of $S \mathbf{- 1}$ is larger than that of tris $\left\{(4\right.$-decyloxyphenyl)isoxazolyl $\}$ benzene $\left(K_{\mathrm{E}}=3.7 \pm 0.3 \mathrm{~L}\right.$ $\left.\mathrm{mol}^{-1}\right) .{ }^{7 d}$ Pt-Pt interactions accompanied by the $\pi-\pi$ stacking and the dipole-dipole interactions drove the assembly of $S-\mathbf{1}$.
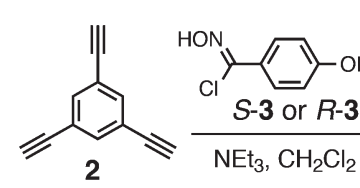<smiles>CC(=O)c1ccc(O)cc1</smiles><smiles>C#Cc1cc(C(C)=CC)cc(-c2ccno2)c1</smiles>

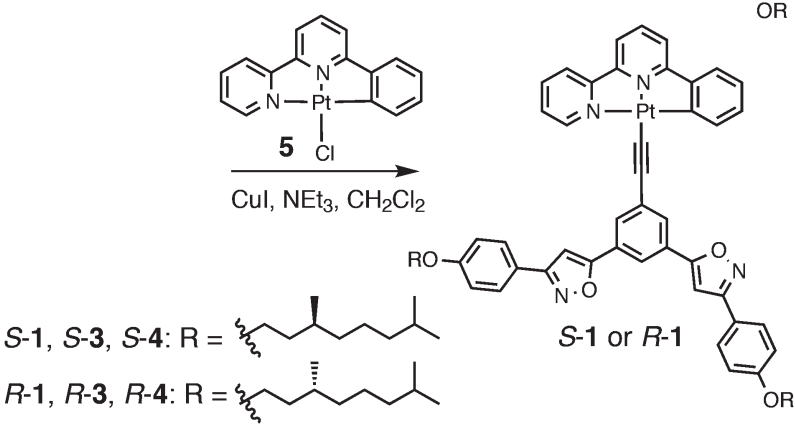

Scheme 2 Synthesis of $\mathrm{Pt}(\mathrm{II})$ phenylbipyridine complexes $S$ - and $R-1$.



Fig. 1 Concentration-dependent ${ }^{1} \mathrm{H}$ NMR spectra of $S-1$ at $298 \mathrm{~K}$ in chloroform- $d_{1}$. The concentrations of $S-1$ are (a) 21.6, (b) 5.6, and (c) $1.0 \mathrm{mmol} \mathrm{L}^{-1}$. *indicates solvent peaks.
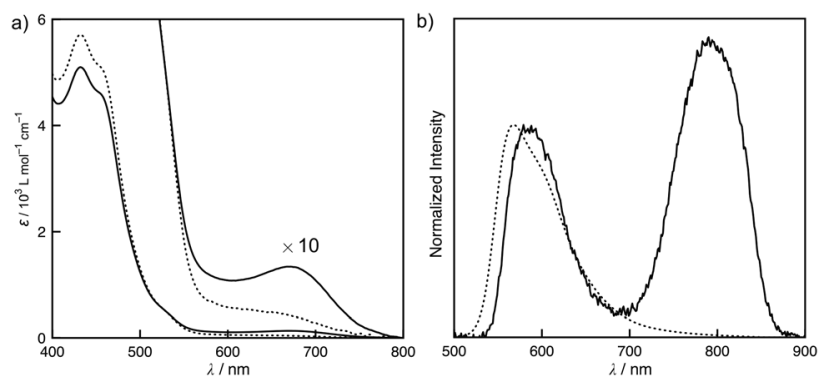

Fig. 2 Concentration-dependent (a) UV-vis absorption and (b) emission spectra of S-1 in chloroform at $25^{\circ} \mathrm{C}$. The concentrations of the solutions are 0.49 (dotted line) and 5.17 (solid line) $\mathrm{mmol} \mathrm{L}^{-1} \cdot \lambda_{\mathrm{ex}}=444 \mathrm{~nm}$.

The absorption and emission spectra of $S$-1 provide insight into the intermolecular interactions throughout the selfassembly. Fig. 2 shows the concentration-dependent absorption and emission spectra of $S \mathbf{- 1}$ in chloroform. At a low concentration, the monomer absorption bands appeared at 431 and $456 \mathrm{~nm}$, which primarily consist of HOMO $\rightarrow$ LUMO and HOMO-2 $\rightarrow$ LUMO excitations given by the TD-DFT calculation (Fig. $\mathrm{S} 4 \dagger$ ). The former transition was assigned to the mixed metal-ligand-to-ligand charge transfer (MLLCT) band. When a solution of $S$-1 was concentrated ten times, a new broad absorption band was obtained at $675 \mathrm{~nm}$, which is recognized as a metal-metal-to-ligand charge transfer (MMLCT) band of the Pt-Pt bonds (Fig. 2a). ${ }^{4,6}$ In the diluted solution of $S$-1, a triplet MLCT emission of $S$-1 was only observed at $568 \mathrm{~nm}$ (Fig. 2b). After concentrating the solution, a ${ }^{3}$ MMLCT emission of the Pt-Pt bonds appeared at $790 \mathrm{~nm} .{ }^{4,6}$ The concentration-dependent MMLCT absorption and emission reveal that the metallophilic interactions of the platinum centers obviously direct the stacked self-assembly of $S-\mathbf{1}$. Our previous studies have shown that tris(phenylisoxazolyl) benzene-based stacked assemblies equilibrate between the $P$ - and $M$-helical structures, which are biased by the presence of chiral side chains in cyclohexane. ${ }^{7 c, d, g}$ In contrast, $S$-1 was 
Circular Dichroism (CD) silent, even in the assembled state (Fig. S6†). Competitive solvation of chloroform most likely resulted in a weak association constant of $93 \mathrm{~L} \mathrm{~mol}^{-1}$, reflecting the limited sizes of the assemblies formed in solution. A high degree of polymerization for the assemblies of $S \mathbf{- 1}$ is required to adopt the helical organization, resulting in tight steric communication between the chiral side chains. The small sizes of the assemblies retain certain flexibility in molecular motions. The quantum yields $(\phi)$ of the phosphorescence decreased $\left(\phi=0.027\right.$ at $[S-1]=5 \times 10^{-4} \mathrm{~mol} \mathrm{~L}^{-1}$ and 0.003 at $\left.[S-1]=5 \times 10^{-3} \mathrm{~mol} \mathrm{~L}^{-1}\right)$ after the assembly.

\section{Helical self-assembly in toluene}

The solvent system directly influenced the molecular assembly of $S$-1. A toluene solution of $S$-1 led to the unique self-assembling behavior. Fig. $3 \mathrm{a}$ and $3 \mathrm{~b}$ display the MLLCT absorption band at $449 \mathrm{~nm}$ and the ${ }^{3}$ MLCT emission band at $573 \mathrm{~nm}$ at $50{ }^{\circ} \mathrm{C}$, which are assignable to the monomeric form of $S-\mathbf{1}$.
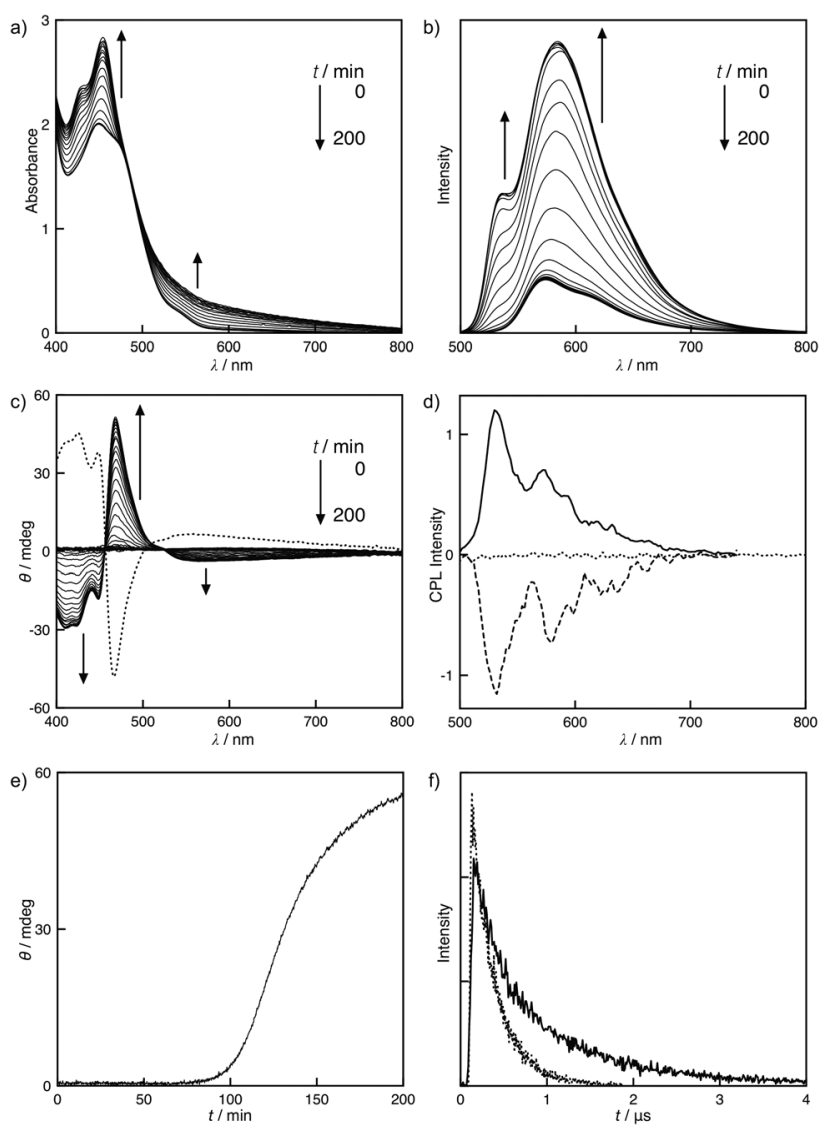

Fig. 3 Time dependent (a) UV-vis absorption and (b) emission spectra of $S-1$ in toluene at $25^{\circ} \mathrm{C}$. (c) CD spectral changes of $S-1$ as a function of time (solid line) and the corresponding spectrum of $R-1$ after the assembly (dotted line) in toluene at $25^{\circ} \mathrm{C}$. (d) CPL spectra of S-1 before (dotted line) and after (solid line) the assembly and $R-1$ after the assembly (dashed line) in toluene at $25^{\circ} \mathrm{C}$. (e) Plot of change in ellipticity $\theta$ at $469 \mathrm{~nm}$ versus time for a solution of $\mathrm{S}-1$ in toluene at $25^{\circ} \mathrm{C}$. (f) Timeresolved emission decay curve of $S-1$ in toluene at $25^{\circ} \mathrm{C}$ before (dotted line) and after (solid line) the assembly. $[S-1]=[R-1]=0.50 \mathrm{mmol} \mathrm{L}^{-1}$. $\lambda_{\mathrm{ex}}=444 \mathrm{~nm}$.
After cooling the toluene solution to $25{ }^{\circ} \mathrm{C}$, an unusual time dependence was observed. New bands at 429 and $454 \mathrm{~nm}$ gradually emerged, implying that the self-assembling process was slow on a human time scale (Fig. 3a). The Pt-Pt bond formation was supported by the broad MMLCT absorption, which appeared at approximately $600 \mathrm{~nm}$ during the self-assembly. Accordingly, the polymeric platinum array was directed by the $\mathrm{Pt}-\mathrm{Pt}$ interaction as well as the $\pi-\pi$ stacking and the dipoledipole interactions in toluene. To determine the size of the assemblies in toluene, dynamic light scattering (DLS) measurements were performed. The large assemblies were formed with a hydrodynamic radius of $1.3 \pm 0.3 \mu \mathrm{m}$ in toluene, while the sizable assemblies were not detected in chloroform (Fig. S8 $\dagger$ ). This slow assembling process was monitored using $\mathrm{CD}$ and emission spectra. When the solution was cooled to $25^{\circ} \mathrm{C}$, the CD was silent. After a brief period, the positive Cotton effects were strongly enhanced at $480 \mathrm{~nm}$, resulting in a dissymmetry factor $g_{\text {abs }}$ of 0.002 , whereas the negative Cotton effects were observed on the MMLCT bands (Fig. 3c). The CD spectra of $S$ - and $R$-1 displayed a mirror image relationship, suggesting that $S$ - and $R$-1 formed helical assemblies, and the helical sense was directed by the chiral side chains. Plots of ellipticity $\theta$ versus time resulted in a sigmoidal response, implying that the assembly process was auto-catalytic (Fig. 3e). The timedependent emission changes were also observed on the assembly. The emission was found at $573 \mathrm{~nm}$ when the solution was cooled to $25{ }^{\circ} \mathrm{C}$. New bands at 535 and $584 \mathrm{~nm}$ emerged after the solution was allowed to sit for a certain amount of time (Fig. 3b).

Unusual AIEE $^{8}$ was observed through the assembly. The emission strongly increased upon the formation of the assembly in toluene (Fig. 3b). The quantum yields of $S$-1 were also time dependent due to the slow assembly. Immediate cooling of the solution of $S-\mathbf{1}$ to $25^{\circ} \mathrm{C}$ resulted in an intense emission with a quantum yield of 0.023 . After stirring for $24 \mathrm{~h}$, the emission became more efficient with a quantum yield of 0.093 . ${ }^{3}$ MMLCT emission band was not found in a toluene solution of $S \mathbf{- 1}$ after the assembly. The emission lifetime measurements of $S \mathbf{- 1}$ in toluene provided more detailed insight into the selfassembly. A rapidly cooled solution of $S-\mathbf{1}$ exhibited a singleexponential emission decay function with a lifetime $\tau$ of $0.28 \mu \mathrm{s}$. When the solution was aged for $24 \mathrm{~h}$, a double-exponential function was observed with lifetimes $\tau_{1}$ and $\tau_{2}$ of 0.25 and $1.1 \mu \mathrm{s}$, respectively (Fig. 3f). Accordingly, $S$-1 exists in two photochemically non-equivalent states: the lifetime $\tau_{1}$ corresponded to the monomeric form, and the long-lived species arose from the self-assembled aggregates. A longer emission lifetime $\tau_{2}$ of $1.1 \mu \mathrm{s}$ reveals that the AIEE is due to the reduction of molecular motion through the self-assembly of $S$-1. The molecular motion is partially restricted in the stacked organization, which suppresses the non-radiative decay channels, thus increasing a portion of the radiative decay process. ${ }^{9}$

Circularly polarized luminescence (CPL) measurements were performed to understand the selective emission of rightand left-handed circularly polarized light from the molecules ${ }^{10}$ and chiral aggregates. ${ }^{4 a, 7 c, 11,12}$ No appreciable CPL was 
observed either from the monomeric state of the molecule or from solutions subjected to analysis immediately after cooling to $25{ }^{\circ} \mathrm{C}$. Interestingly, the helical assembly of $S-\mathbf{1}$ and $R-\mathbf{1}$ exhibited mirror image CPL spectra at the fluorescence wavelength corresponding to the molecular aggregates with a high dissymmetry factor $\left(g_{\text {lum }}\right)$ of 0.01 (Fig. 3d). These findings clearly suggest that the helical assemblies can act as efficient sources of circularly polarized light. Moreover, the CPL of $S$ - and $R-\mathbf{1}$ is regulated via assembling and disassembling of $S-\mathbf{1}$ and $R-\mathbf{1}$, respectively. The observed luminescence dissymmetric factor is significantly larger than the typical $g_{\text {lum }}$ values exhibited by chiral organic molecules. ${ }^{10}$

\section{Polymorphism and memory effect}

An unusual polymorphism and the structural memory effect ${ }^{13}$ were observed in toluene. $S$-1 generated two types of luminescent solids, A and B, obtained by slow evaporation of its chloroform solution and toluene solution, respectively. The ${ }^{1} \mathrm{H}$ NMR spectra of these solids dissolved in chloroform-d were almost identical to one another (Fig. S13†). The emission spectra of these solids were inconsistent with each other. Solid A displayed two emission bands at 564 and $733 \mathrm{~nm}$ corresponding to the ${ }^{3}$ MLCT and ${ }^{3}$ MMLCT bands of the non-helical structures in a chloroform solution of $S-\mathbf{1}$, respectively (Fig. 4a). Solid B generated an emission band at $583 \mathrm{~nm}$, as observed in the helical assemblies in toluene. The weak ${ }^{3}$ MMLCT emission was observed at approximately $750 \mathrm{~nm}$. The quantum yields of solids A and B were 0.003 and 0.025 , respectively (Fig. S12 $\dagger$ ). Accordingly, the assembled structures found in the chloroform and toluene solutions were maintained, even in the solid state (Fig. 2b and 3b). When solid A was dissolved in toluene at room temperature, two emission bands at 574 and $732 \mathrm{~nm}$ unexpectedly corresponded to those of the non-helical structures of the assemblies (Fig. $4 \mathrm{~b}$ dotted line), and the $\mathrm{CD}$ was silent (Fig. S9†). These findings reveal that the non-helical structures are trapped in metastable states in toluene. After warming the solution to $50{ }^{\circ} \mathrm{C}$, the emission band at $732 \mathrm{~nm}$ disappeared, indicating that a monomeric form of $S-1$ was dominant (Fig. $4 \mathrm{~b}$, dashed line). Helical struc-
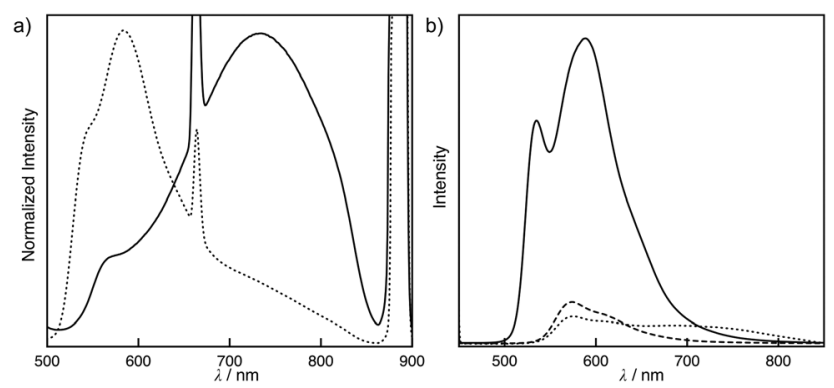

Fig. 4 (a) Emission spectra of solid A (solid line) and solid B (dotted line). (b) Emission spectra at various temperatures of solid $\mathrm{A}$ dissolved in toluene. The temperatures are $25^{\circ} \mathrm{C}$ before heating (dotted line), $50{ }^{\circ} \mathrm{C}$ (dashed line), and $25^{\circ} \mathrm{C}$ after heating (solid line). [S-1] $=0.50 \mathrm{mmol} \mathrm{L}^{-1}$. $\lambda_{\mathrm{ex}}=444 \mathrm{~nm}$. a)
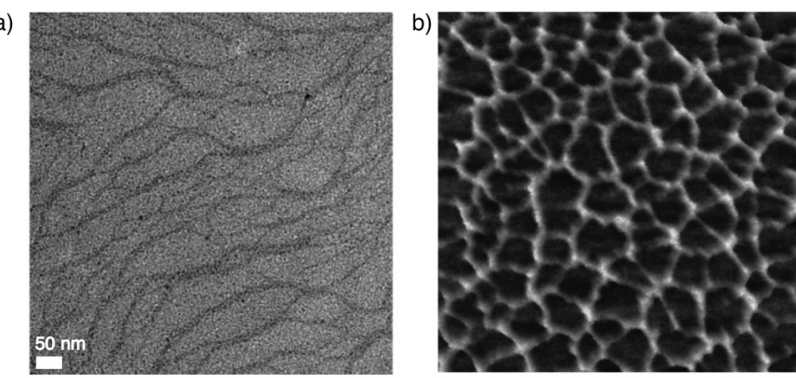

c)
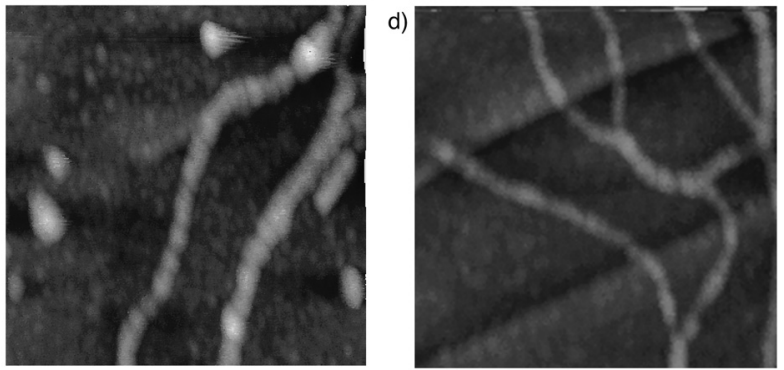

Fig. 5 (a) TEM image of $S-1$. (b) AFM image of $S-1$ on mica. (c), (d) AFM images of S-1 on HOPG. The sizes of the AFM images are (b) $5 \mu \mathrm{m} \times$ $5 \mu \mathrm{m}$, and (c), (d) $500 \mathrm{~nm} \times 500 \mathrm{~nm}$. The samples were prepared from the toluene solution of S-1 after the assembly.

tures developed while the solution was maintained at room temperature for a certain period, displaying the intense emission bands at $580 \mathrm{~nm}$ and the strong Cotton effect (Fig. 3a-c, $4 \mathrm{~b}$, solid line). Although the helical structures were thermodynamically more stable than the non-helical structures in toluene, a sizable energetic barrier existed between the nonhelical and helical forms, the interconversion of which was relatively slow with a half-life of $66 \mathrm{~h}$ at $25^{\circ} \mathrm{C}$ (Fig. S10†).

\section{Microscopic study}

The morphologies of the assemblies of $S-\mathbf{1}$ were observed using transmission electron microscopy (TEM) and atomic force microscopy (AFM). The TEM image of the assembly showed nanofibers with an average width of 5-8 nm (Fig. 5a). The length of the molecule is $c a .1 .8 \mathrm{~nm}$, which indicates that the observed fibers are bundles of the assemblies. The AFM images provided more detailed insights into the assembled structures. When the toluene solution of $S-\mathbf{1}$ was spin-coated on mica, networked fibers with a uniform height of $2 \mathrm{~nm}$ were observed (Fig. 5b and S14†). The height well fit to the length of $S$-1, suggesting that $S$-1 forms a one-dimensional stacked assembly. However, helical fibers were observed when the toluene solution was spin-coated on HOPG (Fig. 5c, d, and $\mathrm{S} 15 \dagger)$. The pitch of the helix is $c a .30 \mathrm{~nm}$. Interestingly, a bundle of the helices was observed (Fig. 5d).

\section{Conclusions}

We demonstrated the unique self-assembling behaviors and optical properties of novel platinum(II) phenylbipyridine 
complexes possessing bis(phenylisoxazolyl)phenylacetylene ligands. $S$-1 formed stacked assemblies in chloroform and in toluene, but the assembled structures were dependent on the solvent properties. In chloroform, $S-\mathbf{1}$ stacked in a non-helical fashion, whereas $S$-1 formed helical assemblies in toluene. The MMLCT absorption and emission bands reveal that the assemblies are directed via the $\mathrm{Pt}-\mathrm{Pt}, \pi-\pi$ stacking, and dipole-dipole interactions. The assembling and disassembling processes in toluene are slow on a human time scale, leading to the structure memory of the non-helical assemblies. The assemblies of $S-\mathbf{1}$, formed in toluene after being aged, display AIEE and AICPL. These emission properties provide possible applications of $S-\mathbf{1}$ as luminescent materials in the solid state or condensed phase.

\section{Experimental section}

5,5'-(5-Ethynyl-1,3-phenylene)bis(3-(4-((S)-3,7-dimethyloctyloxy)phenyl)isoxazole) ( $S$-4)

To a solution of 1,3,5-triethynylbenzene $2(750 \mathrm{mg}, 5.00 \mathrm{mmol})$ and triethylamine $(7.0 \mathrm{ml}, 50 \mathrm{mmol})$ in $\mathrm{CH}_{2} \mathrm{Cl}_{2}(50 \mathrm{ml})$ was added chlorooxime $S-3(3.22 \mathrm{~g}, 10.3 \mathrm{mmol})$ in $\mathrm{CH}_{2} \mathrm{Cl}_{2}(10 \mathrm{ml})$. After being stirred at room temperature for 1 day under an argon atmosphere, the reaction mixture was concentrated in vacuo. The crude product was purified by column chromatography on silica gel (EtOAc/hexane) to give $S-4$ (696 mg, 20\%) as a white solid. M.p. $98-99{ }^{\circ} \mathrm{C} ;{ }^{1} \mathrm{H}$ NMR $\left(300 \mathrm{MHz}, \mathrm{CDCl}_{3}\right)$ : $\delta 8.24(\mathrm{t}, J=3.0 \mathrm{~Hz}, 1 \mathrm{H}), 7.98(\mathrm{~d}, J=3.0 \mathrm{~Hz}, 2 \mathrm{H}), 7.79(\mathrm{~d}, J=$ $9.7 \mathrm{~Hz}, 4 \mathrm{H}), 6.99(\mathrm{~d}, J=9.7 \mathrm{~Hz}, 4 \mathrm{H}), 6.89(\mathrm{~s}, 2 \mathrm{H}), 4.05(\mathrm{t}, J=$ $7.7 \mathrm{~Hz}, 4 \mathrm{H}), 3.24(\mathrm{~s}, 1 \mathrm{H}), 1.90-1.81(\mathrm{~m}, 4 \mathrm{H}), 1.75-1.47(\mathrm{~m}, 8 \mathrm{H})$, $1.42-1.10(\mathrm{~m}, 8 \mathrm{H}), 0.96(\mathrm{~d}, J=7.0 \mathrm{~Hz}, 6 \mathrm{H})$, and $0.88(\mathrm{~d}, J=7.3$ $\mathrm{Hz}, 6 \mathrm{H}) \mathrm{ppm} ;{ }^{13} \mathrm{C}$ NMR $\left(75 \mathrm{MHz}, \mathrm{CDCl}_{3}\right.$ ): $\delta 168.3,163.0,161.0$, 130.6, 128.9, 128.4, 124.3, 123.1, 121.1, 115.1, 98.8, 82.0, 79.6, $66.7,39.5,37.5,36.3,30.1,28.2,24.9,22.9$, and $19.9 \mathrm{ppm}$; IR (KBr): $\nu$ 2952, 2925, 2867, 2095, 1612, 1562, 1488, 1462，1438，1385，1294，1252，1176，1115，949，877，836, 791 , and $649 \mathrm{~cm}^{-1}$; HRMS $\left(\mathrm{ESI}^{+}\right)$calcd for $\mathrm{C}_{46} \mathrm{H}_{57} \mathrm{~N}_{2} \mathrm{O}_{4} \mathrm{~m} / \mathrm{z}$ $701.4316[\mathrm{M}+\mathrm{H}]^{+}$, found $\mathrm{m} / \mathrm{z}$ 701.4313; Anal. calcd for $\mathrm{C}_{46} \mathrm{H}_{56} \mathrm{~N}_{2} \mathrm{O}_{4}: \mathrm{C} 78.82, \mathrm{H} 8.05, \mathrm{~N} 4.00$, found $\mathrm{C} 78.76$, $\mathrm{H} 8.02, \mathrm{~N} 4.02 \%$.

\section{5,5'-(5-Ethynyl-1,3-phenylene)bis(3-(4-((R)-3,7-dimethyl-} octyloxy)phenyl)isoxazole) $(R-4)$

To a solution of 1,3,5-triethynylbenzene 2 ( $403 \mathrm{mg}, 2.68 \mathrm{mmol}$ ) and triethylamine $(3.6 \mathrm{ml}, 26 \mathrm{mmol})$ in $\mathrm{CH}_{2} \mathrm{Cl}_{2}(10 \mathrm{ml})$ was added chlorooxime $R-3(1.67 \mathrm{~g}, 5.37 \mathrm{mmol})$ in $\mathrm{CH}_{2} \mathrm{Cl}_{2}(10 \mathrm{ml})$. After being stirred at room temperature for 1 day under an argon atmosphere, the reaction mixture was concentrated in vacuo. The crude product was purified by column chromatography on silica gel (EtOAc/hexane) to give $R-4$ (300 mg, 16\%) as a white solid. M.p. $98-99{ }^{\circ} \mathrm{C} ;{ }^{1} \mathrm{H}$ NMR $\left(300 \mathrm{MHz}, \mathrm{CDCl}_{3}\right)$ : $\delta 8.25(\mathrm{t}, J=3.0 \mathrm{~Hz}, 1 \mathrm{H}), 8.00(\mathrm{~d}, J=3.0 \mathrm{~Hz}, 2 \mathrm{H}), 7.81(\mathrm{~d}, J=$ $9.7 \mathrm{~Hz}, 4 \mathrm{H}), 7.01(\mathrm{~d}, J=9.7 \mathrm{~Hz}, 4 \mathrm{H}), 6.91(\mathrm{~s}, 2 \mathrm{H}), 4.06(\mathrm{~m}, 4 \mathrm{H})$, $3.24(\mathrm{~s}, 1 \mathrm{H}), 1.90-1.81(\mathrm{~m}, 4 \mathrm{H}), 1.75-1.47(\mathrm{~m}, 8 \mathrm{H}), 1.42-1.10$ (m, 8H), $0.96(\mathrm{~d}, J=7.0 \mathrm{~Hz}, 6 \mathrm{H})$, and $0.88(\mathrm{~d}, J=7.3 \mathrm{~Hz}, 6 \mathrm{H})$ ppm; ${ }^{13} \mathrm{C}$ NMR $\left(75 \mathrm{MHz}, \mathrm{CDCl}_{3}\right): \delta 168.3,163.1,161.0130 .6$, 128.9, 128.4, 124.3, 123.1, 121.1, 115.2, 98.8, 82.0, 79.6, 66.7, $39.5,37.5,36.3,30.1,28.2,24.9,22.8$, and 19.9 ppm; IR (KBr): $\nu$ 2952, 2925, 2095, 1611, 1564, 1526, 1488, 1460, 1439, 1385, 1295, 1251, 1176, 949, 876, 836, 790, 756, 730, and $649 \mathrm{~cm}^{-1}$; HRMS (ESI ${ }^{+}$) calcd for $\mathrm{C}_{46} \mathrm{H}_{57} \mathrm{~N}_{2} \mathrm{O}_{4} \mathrm{~m} / z 701.4321[\mathrm{M}+\mathrm{H}]^{+}$, found $\mathrm{m} / \mathrm{z}$ 701.4313; Anal. calcd for $\mathrm{C}_{46} \mathrm{H}_{56} \mathrm{~N}_{2} \mathrm{O}_{4}$ : C 78.82, $\mathrm{H} 8.05, \mathrm{~N} 4.00$, found C 78.81, H 8.09, N 4.02\%.

(6-Phenyl-2,2'-bipyridine)\{5,5'-(5-ethynyl-1,3-phenylene)bis(3(4-((S)-3,7-dimethyloctyloxy)phenyl)isoxazole)\}platinum (S-1)

To a solution of (6-phenyl-2,2'-bipyridine)chloroplatinum 5 $(113 \mathrm{mg}, 244 \mu \mathrm{mol})$ and ligand $S-4(171 \mathrm{mg}, 244 \mu \mathrm{mol})$ in $\mathrm{CH}_{2} \mathrm{Cl}_{2}(5 \mathrm{ml})$ and DMF $(5 \mathrm{ml})$ was added triethylamine $(0.5 \mathrm{ml}, 3.6 \mathrm{mmol})$. The mixture was degassed by bubbling argon for $30 \mathrm{~min}$. CuI ( $8 \mathrm{mg}, 42 \mu \mathrm{mol})$ was added to the reaction mixture and the resulting mixture was stirred at room temperature for 1 day under an argon atmosphere in the dark. The reaction mixture was extracted with $\mathrm{CH}_{2} \mathrm{Cl}_{2}$ and the organic layer was washed with brine, dried over $\mathrm{Na}_{2} \mathrm{SO}_{4}$ and concentrated in vacuo. The crude product was further purified by column chromatography on silica gel (EtOAc/hexane, $\left.\mathrm{CHCl}_{3} / \mathrm{MeOH}\right)$ to give $S-\mathbf{1}(216 \mathrm{mg}, 79 \%)$ as an orange solid. M.p. $221-222{ }^{\circ} \mathrm{C} ;{ }^{1} \mathrm{H}$ NMR $\left(300 \mathrm{MHz}, \mathrm{CDCl}_{3}\right): \delta 9.21$ (d, $J=$ $6.0 \mathrm{~Hz}, 1 \mathrm{H}), 8.04(\mathrm{~s}, 1 \mathrm{H}), 8.04(\mathrm{~s}, 2 \mathrm{H}), 8.04-7.95(\mathrm{~m}, 1 \mathrm{H}), 7.94$ $(\mathrm{d}, J=7.7 \mathrm{~Hz}, 1 \mathrm{H}), 7.81(\mathrm{~d}, J=9.7 \mathrm{~Hz}, 4 \mathrm{H}), 7.82-7.76(\mathrm{~m}, 2 \mathrm{H})$, $7.57(\mathrm{~d}, J=6.7 \mathrm{~Hz}, 1 \mathrm{H}), 7.55-7.52(\mathrm{~m}, 1 \mathrm{H}), 7.49(\mathrm{~d}, J=3.3 \mathrm{~Hz}$, $1 \mathrm{H}), 7.29(\mathrm{t}, J=6.7 \mathrm{~Hz}, 1 \mathrm{H}), 7.20(\mathrm{~d}, J=10 \mathrm{~Hz}, 1 \mathrm{H}), 7.05(\mathrm{t}, J=$ $6.7 \mathrm{~Hz}, 1 \mathrm{H}), 6.99(\mathrm{~d}, J=10 \mathrm{~Hz}, 4 \mathrm{H}), 6.86(\mathrm{~s}, 2 \mathrm{H}), 4.05(\mathrm{t}, J=$ $3.3 \mathrm{~Hz}, 4 \mathrm{H}), 1.93-1.78(\mathrm{~m}, 4 \mathrm{H}), 1.75-1.48(\mathrm{~m}, 8 \mathrm{H}), 1.43-1.09$ $(\mathrm{m}, 8 \mathrm{H}), 0.96(\mathrm{~d}, J=10 \mathrm{~Hz}, 6 \mathrm{H})$, and $0.88(\mathrm{~d}, J=6.7 \mathrm{~Hz}, 12 \mathrm{H})$ ppm; ${ }^{13} \mathrm{C}$ NMR $\left(75 \mathrm{MHz}, \mathrm{CDCl}_{3}\right): \delta 169.6,165.7,162.9,160.9$, 158.0, 154.6, 152.2, 146.9, 142.1, 139.1, 139.0, 138.6, 131.8, $130.6,128.4,128.1,127.9,124.8,124.1,122.7,121.5,119.5$, 118.7, 117.8, 115.1, 104.8, 98.15, 66.7, 39.5, 37.5, 36.4, 30.1, 28.21, 24.9, 22.8, and $19.9 \mathrm{ppm}$; IR (KBr): $\nu$ 3207, 2954, 2927, 2870, 1613, 1564, 1528, 1462, 1442, 1385, 1295, 1252, 1177, 1115, 1018, 950, 879, 837, 790, and $764 \mathrm{~cm}^{-1}$; HRMS $\left(\mathrm{ESI}^{+}\right)$ calcd for $\mathrm{C}_{62} \mathrm{H}_{66} \mathrm{~N}_{4} \mathrm{O}_{4} \mathrm{NaPt} m / z 1148.4630[\mathrm{M}+\mathrm{Na}]^{+}$, found $\mathrm{m} / \mathrm{z}$ 1148.4630; Anal. calcd for $\mathrm{C}_{62} \mathrm{H}_{66} \mathrm{~N}_{4} \mathrm{O}_{4} \mathrm{Pt} \cdot\left(\mathrm{H}_{2} \mathrm{O}\right)_{1.3}$ : C 64.77, H 6.01, N 4.87, found C 64.59, H 5.97, N 4.71\%.

(6-Phenyl-2,2'-bipyridine)\{5,5'-(5-ethynyl-1,3-phenylene)bis(3(4-((R)-3,7-dimethyloctyloxy)phenyl)isoxazole)\}platinum ( $R-1)$

To a solution of (6-phenyl-2,2'-bipyridine)chloroplatinum 5 $(107 \mathrm{mg}, 232 \mu \mathrm{mol})$ and isoxazolylbenzene $R-4$ (300 mg, $428 \mu \mathrm{mol})$ in $\mathrm{CH}_{2} \mathrm{Cl}_{2}(10 \mathrm{ml})$ was added triethylamine $(0.5 \mathrm{ml}$, $3.6 \mathrm{mmol})$. The mixture was degassed by bubbling argon for $30 \mathrm{~min}$. CuI $(10 \mathrm{mg}, 53 \mu \mathrm{mol})$ was added to the reaction mixture and the resulting mixture was stirred at room temperature for 1 day under an argon atmosphere in the dark. The reaction mixture was extracted with $\mathrm{CH}_{2} \mathrm{Cl}_{2}$ and the organic layer was washed with brine, dried over $\mathrm{Na}_{2} \mathrm{SO}_{4}$ and concentrated in vacuo. The crude product was further purified by column chromatography on silica gel (EtOAc/hexane, $\mathrm{CHCl}_{3}$ / $\mathrm{MeOH})$ to give $R-\mathbf{1}(195 \mathrm{mg}, \mathbf{7 5 \%})$ as an orange solid. M.p. 
221-222 ${ }^{\circ} \mathrm{C} ;{ }^{1} \mathrm{H}$ NMR $\left(300 \mathrm{MHz}, \mathrm{CDCl}_{3}\right): \delta 9.15(\mathrm{~d}, J=6.0 \mathrm{~Hz}$, $1 \mathrm{H}), 8.03$ (s, 1H), 8.03 (s, 2H), 8.04-7.95 (m, 2H), 7.81 (d, $J=$ $9.7 \mathrm{~Hz}, 4 \mathrm{H}), 7.82-7.72(\mathrm{~m}, 2 \mathrm{H}), 7.58-7.52(\mathrm{~m}, 2 \mathrm{H}), 7.48(\mathrm{~d}, J=$ $3.3 \mathrm{~Hz}, 1 \mathrm{H}), 7.30$ (d, $J=6.7 \mathrm{~Hz}, 1 \mathrm{H}), 7.20$ (t, $J=10 \mathrm{~Hz}, 1 \mathrm{H}), 7.05$ (t, $J=6.7 \mathrm{~Hz}, 1 \mathrm{H}), 6.99(\mathrm{~d}, J=10 \mathrm{~Hz}, 4 \mathrm{H}), 6.86(\mathrm{~s}, 2 \mathrm{H}), 4.05(\mathrm{t}$, $J=3.3 \mathrm{~Hz}, 4 \mathrm{H}), 1.93-1.78$ (m, 4H), 1.75-1.48 (m, 8H), 1.43-1.09 $(\mathrm{m}, 8 \mathrm{H}), 0.96(\mathrm{~d}, J=10 \mathrm{~Hz}, 6 \mathrm{H})$, and $0.88(\mathrm{~d}, J=6.7 \mathrm{~Hz}, 12 \mathrm{H})$ ppm; ${ }^{13} \mathrm{C}$ NMR (75 MHz, $\mathrm{CDCl}_{3}$ ): $\delta$ 169.6, 165.7, 162.9, 160.9, $158.0,154.7,151.9,147.0,142.1$, 139.1, 139.0, 138.6, 131.8, $130.5,128.4,128.1,127.9,124.7,124.1,122.9,121.5,119.5$, 118.6, 117.9, 115.1, 104.9, 98.24, 66.7, 39.5, 37.5, 36.4, 30.1, 28.21, 24.9, 22.8, and $19.9 \mathrm{ppm}$; IR (KBr): $\nu$ 3737, 3567, 2954, 2927, 2870, 1717, 1613, 1563, 1528, 1509, 1459, 1385, 1295, 1177, 1115, 1018, 950, 837, 790, and $765 \mathrm{~cm}^{-1}$; HRMS $\left(\mathrm{ESI}^{+}\right)$ calcd for $\mathrm{C}_{62} \mathrm{H}_{66} \mathrm{~N}_{4} \mathrm{O}_{4} \mathrm{NaPt} m / z 1148.4630[\mathrm{M}+\mathrm{Na}]^{+}$, found $m / z$ 1148.4624; Anal. calcd for $\mathrm{C}_{62} \mathrm{H}_{66} \mathrm{~N}_{4} \mathrm{O}_{4} \mathrm{Pt} \cdot\left(\mathrm{H}_{2} \mathrm{O}\right)_{1.3}$ : C 64.77, H 6.01, N 4.87, found C 64.61, H 5.78, N 4.69\%.

\section{Acknowledgements}

This work was supported by Grant-in-Aids for Scientific Research (B) (no. 24350060), Challenging Exploratory Research (no. 23655105), and Grant-in Aids for Young Scientists (B) (no. 26810051) of JSPS, as well as Grant-in-Aids for Scientific Research on Innovative Areas, "Stimuli-responsive Chemical Species for Creation of Functional Molecules" and "New Polymeric Materials Based on Element-Blocks" (no. 25109529, 25102532), and Platform for Dynamic Approaches to Living System of MEXT.

\section{Notes and references}

1 (a) S. I. Stupp and L. C. Palmer, Chem. Mater., 2014, 26, 507; (b) H. Li, J. Choi and T. Nakanishi, Langmuir, 2013, 29, 5394; (c) F. Würthner, T. E. Kaiser and C. R. Saha-Möller, Angew. Chem., Int. Ed., 2011, 50, 3376; (d) P. M. Beaujuge and J. M. J. Fréchet, J. Am. Chem. Soc., 2011, 133, 20009; (e) L. Zang, Y. Che and J. S. Moore, Acc. Chem. Res., 2008, 41, 1596; $(f)$ T. Kato, N. Mizoshita and K. Kishimoto, Angew. Chem., Int. Ed., 2006, 45, 38; $(g)$ F. J. M. Hoeben, P. Jonkheijm, E. W. Meijer and A. P. H. J. Schenning, Chem. Rev., 2005, 105, 1491.

2 (a) Y. Chen, G. Cheng, K. Li, D. P. Shelar, W. Lu and C.-M. Che, Chem. Sci., 2014, 5, 1348; (b) J.-J. Zhang, W. Lu, R. W.-Y. Sun and C.-M. Che, Angew. Chem., Int. Ed., 2012, 51, 4882; (c) W. Lu, K. T. Chan, S.-X. Wu, Y. Chen and C.-M. Che, Chem. Sci., 2012, 3, 752; (d) H. O. Lintang, K. Kinbara, K. Tanaka, T. Yamashita and T. Aida, Angew. Chem., Int. Ed., 2010, 49, 4241; (e) A. Kishimura, T. Yamashita and T. Aida, J. Am. Chem. Soc., 2005, 127, 179.

3 M. J. Mayoral, C. Rest, V. Stepanenko, J. Schellheimer, R. Q. Albuquerque and G. Fernández, J. Am. Chem. Soc., 2013, 135, 2148.
4 (a) X.-P. Zhang, V. Y. Chang, J. Liu, X.-L. Yang, W. Huang, Y. Li, C.-H. Li, G. Muller and X.-Z. You, Inorg. Chem., 2015, 54, 143; (b) M. Krikorian, S. Liu and T. M. Swager, J. Am. Chem. Soc., 2014, 136, 2952; (c) R. Sekiya, Y. Tsutsui, W. Choi, T. Sakurai, S. Seki, Y. Bando and H. Maeda, Chem. Commun., 2014, 50, 10615; (d) S. Y.-L. Leung and V. W.-W. Yam, Chem. Sci., 2013, 4, 4228; (e) K. M.-C. Wong and V. W.-W. Yam, Acc. Chem. Res., 2011, 44, 424; $(f)$ C. Po, A. Y.-Y. Tam, K. M.-C. Wong and V. W.-W. Yam, J. Am. Chem. Soc., 2011, 133, 12136; $(g)$ W. Lu, Y. Chen, V. A. L. Roy, S. S.-Y. Chui and C.-M. Che, Angew. Chem., Int. Ed., 2009, 48, 7621; (h) M.-Y. Yuen, V. A. L. Roy, W. Lu, S. C. F. Kui, G. S. M. Tong, M.-H. So, S. S.-Y. Chui, M. Muccini, J. Q. Ning, S. J. Xu and C.-M. Che, Angew. Chem., Int. Ed., 2008, 47, 9895.

5 (a) N. Lanigan and X. Wang, Chem. Commun., 2013, 49, 8133; (b) H. Xiang, J. Cheng, X. Ma, X. Zhou and J. J. Chruma, Chem. Soc. Rev., 2013, 42, 6128; (c) I. Eryazici, C. N. Moorefield and G. R. Newkome, Chem. Rev., 2008, 108, 1834.

6 (a) A. Amar, H. Meghezzi, J. Boixel, H. Le Bozec, V. Guerchais, D. Jacquemin and A. Boucekkine, J. Phys. Chem. A, 2014, 118, 6278; (b) M. Mauro, A. Aliprandi, C. Cebrián, D. Wang, C. Kübel and L. De Cola, Chem. Commun., 2014, 50, 7269; (c) Y.-J. Tian, E. W. Meijer and F. Wang, Chem. Commun., 2013, 49, 9197; (d) A. Gross, T. Moriuchi and T. Hirao, Chem. Commun., 2013, 49, 1163; (e) T. Moriuchi, Y. Sakamoto, S. Noguchi, T. Fujiwara, S. Akine, T. Nabeshima and T. Hirao, Dalton Trans., 2012, 41, 8524; $(f)$ C. A. Strassert, C.-H. Chien, M. D. G. Lopez, D. Kourkoulos, D. Hertel, K. Meerholz and L. De Cola, Angew. Chem., Int. Ed., 2011, 50, 946.

7 (a) T. Haino, Y. Ueda, T. Hirao, T. Ikeda and M. Tanaka, Chem. Lett., 2014, 43, 414; (b) T. Haino, Y. Hirai, T. Ikeda and H. Saito, Org. Biomol. Chem., 2013, 11, 4164; (c) T. Ikeda, T. Masuda, T. Hirao, J. Yuasa, H. Tsumatori, T. Kawai and T. Haino, Chem. Commun., 2012, 48, 6025; (d) M. Tanaka, T. Ikeda, J. Mack, N. Kobayashi and T. Haino, J. Org. Chem., 2011, 76, 5082; (e) T. Haino and H. Saito, Aust. J. Chem., 2010, 63, 640; (f) T. Haino and H. Saito, Synth. Met., 2009, 159, 821; $(g)$ T. Haino, M. Tanaka and Y. Fukazawa, Chem. Commun., 2008, 468; (h) M. Tanaka, T. Haino, K. Ideta, K. Kubo, A. Mori and Y. Fukazawa, Tetrahedron, 2007, 63, 652; (i) T. Haino, M. Tanaka, K. Ideta, K. Kubo, A. Mori and Y. Fukazawa, Tetrahedron Lett., 2004, 45, 2277.

8 (a) J. Seo, J. W. Chung, J. E. Kwon and S. Y. Park, Chem. Sci., 2014, 5, 4845; (b) R. Hu, N. L. C. Leung and B. Z. Tang, Chem. Soc. Rev., 2014, 43, 4494; (c) Y. Hong, J. W. Y. Lam and B. Z. Tang, Chem. Soc. Rev., 2011, 40, 5361; (d) Z. Zhao, S. Chen, X. Shen, F. Mahtab, Y. Yu, P. Lu, J. W. Y. Lam, H. S. Kwok and B. Z. Tang, Chem. Commun., 2010, 46, 686; (e) Y. Hong, J. W. Y. Lam and B. Z. Tang, Chem. Commun., 2009, 4332.

9 The AIEE might be due to the restricted rotation of the $\mathrm{C}\left(\mathrm{sp}^{2}\right)-\mathrm{C}(\mathrm{sp})$ bonds in the aggregated structures. See the 
following reference: S. K. Albert, H. V. P. Thelu, M. Golla, N. Krishnan, S. Chaudhary and R. Varghese, Angew. Chem., Int. Ed., 2014, 53, 8352-8357.

10 (a) C. Shen, E. Anger, M. Srebro, N. Vanthuyne, K. K. Deol, T. D. Jefferson, G. Muller, J. A. G. Williams, L. Toupet, C. Roussel, J. Autschbach, R. Réau and J. Crassous, Chem. Sci., 2014, 5, 1915; (b) Y. Morisaki, M. Gon, T. Sasamori, N. Tokitoh and Y. Chujo, J. Am. Chem. Soc., 2014, 136, 3350; (c) H. Oyama, K. Nakano, T. Harada, R. Kuroda, M. Naito, K. Nobusawa and K. Nozaki, Org. Lett., 2013, 15, 2104; (d) H. Maeda, Y. Bando, K. Shimomura, I. Yamada, M. Naito, K. Nobusawa, H. Tsumatori and T. Kawai, J. Am. Chem. Soc., 2011, 133, 9266; (e) J. E. Field, G. Muller, J. P. Riehl and D. Venkataraman, J. Am. Chem. Soc., 2003, 125, 11808; $(f)$ E. Peeters, M. P. T. Christiaans, R. A. J. Janssen, H. F. M. Schoo, H. P. J. M. Dekkers and E. W. Meijer, J. Am. Chem. Soc., 1997, 119, 9909; (g) J. P. Riehl and F. S. Richardson, Chem. Rev., 1986, 86, 1.

11 (a) H. Maeda, W. Hane, Y. Bando, Y. Terashima, Y. Haketa, H. Shibaguchi, T. Kawai, M. Naito, K. Takaishi, M. Uchiyama and A. Muranaka, Chem. - Eur. J., 2013, 19, 16263; (b) J. Liu, H. Su, L. Meng, Y. Zhao, C. Deng, J. C. Y. Ng, P. Lu, M. Faisal, J. W. Y. Lam, X. Huang, H. Wu, K. S. Wong and B. Z. Tang, Chem. Sci., 2012, 3, 2737; (c) A. Gopal, M. Hifsudheen, S. Furumi, M. Takeuchi and A. Ajayaghosh, Angew. Chem., Int. Ed., 2012, 51, 10505; (d) T. Kaseyama, S. Furumi, X. Zhang, K. Tanaka and
M. Takeuchi, Angew. Chem., Int. Ed., 2011, 50, 3684; (e) F. C. Spano, S. C. J. Meskers, E. Hennebicq and D. Beljonne, J. Am. Chem. Soc., 2007, 129, 7044; (f) A. Satrijo, S. C. J. Meskers and T. M. Swager, J. Am. Chem. Soc., 2006, 128, 9030; (g) K. E. S. Phillips, T. J. Katz, S. Jockusch, A. J. Lovinger and N. J. Turro, J. Am. Chem. Soc., 2001, 123, 11899.

12 (a) J. Kumar, T. Nakashima, H. Tsumatori and T. Kawai, J. Phys. Chem. Lett., 2014, 5, 316; (b) J. Kumar, T. Nakashima, H. Tsumatori, M. Mori, M. Naito and T. Kawai, Chem. - Eur. J., 2013, 19, 14090; (c) H. Tsumatori, T. Nakashima and T. Kawai, Org. Lett., 2010, 12, 2362; (d) H. Tsumatori, T. Nakashima, J. Yuasa and T. Kawai, Synth. Met., 2009, 159, 952.

13 (a) J.-S. Zhao, Y.-B. Ruan, R. Zhou and Y.-B. Jiang, Chem. Sci., 2011, 2, 937; (b) F. Helmich, C. C. Lee, A. P. H. J. Schenning and E. W. Meijer, J. Am. Chem. Soc., 2010, 132, 16753; (c) A. Mammana, A. D’Urso, R. Lauceri and R. Purrello, J. Am. Chem. Soc., 2007, 129, 8062; (d) M. Ziegler, A. V. Davis, D. W. Johnson and K. N. Raymond, Angew. Chem., Int. Ed., 2003, 42, 665; (e) L. J. Prins, F. De Jong, P. Timmerman and D. N. Reinhoudt, Nature, 2000, 408, 181; $(f)$ A. Sugasaki, M. Ikeda, M. Takeuchi, A. Robertson and S. Shinkai, J. Chem. Soc., Perkin Trans. 1, 1999, 3259; (g) Y. Furusho, T. Kimura, Y. Mizuno and T. Aida, J. Am. Chem. Soc., 1997, 119, 5267. 